\title{
Research on Risk Assessment for Equipment Development Based on Set Pair Analysis
}

\author{
Xusheng Gan ${ }^{1, \text { a }}$, Jingjuan Sun ${ }^{2, \text { b }}$, Guozhou Yang ${ }^{2, c}$ \\ ${ }^{1}$ Xijing College, Xi’an, Shaanxi, 710123, China \\ ${ }^{2}$ Air Traffic Control and Navigation College, Air Force Engineering, University, Xi’an, Shaanxi, 710051, \\ China \\ aganxusheng123@163.com, bsunjj6768@163.com, 'ygz123@163.com
}

Keywords: Set pair analysis; Equipment development; Risk assessment; Connection degree; Assessment criteria

\begin{abstract}
In order to improve the capacity of risk assessment for equipment development, a risk assessment method based on Set Pair Analysis (SPA) is proposed. On the basis of built index system of equipment development risk assessment, SPA method is introduced to perform the risk assessment for equipment development. The calculation example shows that the proposed method has satisfactory assessment capacity. This verifies the feasible and effectiveness of proposed method.
\end{abstract}

\section{Introduction}

Development of modern weapon equipment uses a large number of new technologies with high demand, big investment and long time, and there are also great risks. At the same time, the development risks are also moving in the direction of diversification, complication and frequent occurrence. There is a general problem of rising funds, dropping targets and dragging progress, bringing enormous pressure on the development work. In order to effectively reduce or evade risks, the risks need to be identified and evaluated in advance to provide theoretical and technical support for the management and decision-making of weapons and equipment projects.

In the 1960s, the U.S. Department of Defense began to pay attention to the risk of weapon equipment development. Since 1979, risk analysis has been taken as an important partial of equipment procurement, and the essence of acquisition project management was considered as risk management [1]. By the late 1980s, European Space Agency (ESA) developed risk assessment requirements and methods, and pointed out that, the risk assessment is a tool supporting decision-making, the danger causes the risk, and the risk assessment is based on progressive analysis method throughout the entire project and system life cycle. In "Risk Management of National Defense Acquisition", the risk is divides into 5 levels from A to E, and the criterion is the deviation of the risk event from the known standard or best practice. The deviation degree from $\mathrm{A}$ to $\mathrm{E}$ corresponds to the smallest, Acceptable, great and greater respectively [2]. Theory and practice show that, in risk management of equipment development, the comprehensive assessment of equipment development risk is of crucial importance.

According to above analysis, Set Pair Analysis (SPA) is introduced to propose a new assessment method for equipment development risk. By quantifying the risk factors, the transformation of equipment development risk is realized from qualitative analysis to quantitative assessment, so as to reduce the influence of subjective factors on the assessment model. The example shows that the method can assess the risk of equipment development scientifically and provide a reference for equipment development decision. 


\section{Index system of equipment development risk assessment}

Establishing the index system is the most important step in the risk assessment of equipment development. Taking an anti-aircraft and anti-missile equipment research project of Air Force as an example, the risk factors include the following [3]:

1) Project risk factors. Military attitude: the system's technical and tactical performance indices and other needs usually are proposed by the military, the military support is essential. Market demand: domestic and international market demand determines the actual value of equipment development, and reflects in the two aspects of technological innovation and economic benefits.

2) Development risk factors. Technical storage: The necessary technical storage determines whether the enterprise can finish the equipment development and production within the stipulated standard and time. Talent introduction: The equipment development institute shall possess the necessary technical capacity and talent storage to ensure the smooth development of the development project.

3) Production risk factors. Technological level: the production technology seriously affects the technical and tactical performance, the gap of technological level also determines the compatibility of weapons systems. Material supplies: development costs and the supply of partials affect the progress of the project development and technical indices.

4) Technology risk factors. Technology innovation: excessive use of new technologies increases the technical risks, and even affects the equipment outfit and use; test identification: the lack of adequate testing and identification result in the difficulties to find equipment design errors with increase of development costs, and it cannot meet the performance requirements.

5) Capital risk factors. Budget expenditure: If there are problems of fund raising and budget management, it will delay the progress of development and exceed the budget. Cost Control: lax cost controlling resulting in cost increases, will have an impact on equipment development.

6) Management risk factors. Project management: If the technical and tactical indices are set too high, resulting in the risk such as progress, cost or quality and so on, or cost estimates and quality supervision is not enough, leading to cost increase and quality degradation. Evaluation supervision: the lack of assessment on costs, technology and Progress, or the lack of intermediate node review, result in losing the opportunity for comprehensive evaluation.

\section{Set pair analysis theory}

The mathematical expression of SPA method: the problem to be solved is defined, and the data set $A$ and data set $B$ are combined into a set pair. The characteristics of the set pair $\Theta$ is analyzed, getting totally $N$ characteristics, where $N$ characteristics is the common ownership of the set $A$ and $B$ in the set pair $\Theta$, that is 'identity'; $P$ characteristics is antagonistic to the set $A$ and $B$, that is 'antagonism'; The rest of characteristics, namely $F=N-P-S$, are neither opposed nor jointly owned to the set $A$ and $B$, that is 'difference'. Then, $S / N$ can be called as the identity degree under the set problem; $F / N$ can be called as the difference degree under the set problem; $P / N$ can be called as the antagonism degree under the set problem [4][5]. Without considering the weight, to reflect the contact and transformation of the three, it can be specifically expressed as

$$
\mu=\frac{S}{N}+\frac{F}{N} i+\frac{P}{N} j
$$

The above formula can also be expressed as

$$
\mu=a+b i+c j
$$

where, $\mu$ is the connection degree, $a=S / N$ is the identity degree, $b=F / N$ is the difference degree, $c=P$ / $N$ is the antagonism degree, and $a+b+c=1$. $i$ is the coefficient of difference degree, and the value interval is $i \in[1,-1]$. When $i$ has a practical meaning, $i=1$, the difference degree $b$ is transformed into the identity degree $a \cdot i=-1$, the difference degree $b$ is transformed into the 
antagonism degree $c . i \in(1,-1)$ the identity degree $a$ and antagonism degree $c$ occupy a certain percentage respectively. $j$ is the coefficient of antagonism degree, and its value is -1 .

Considering the weight of each characteristic, the connection degree is

$$
\mu_{W}=\sum_{k=1}^{S} \omega_{k}+\sum_{k=S+1}^{S+F} \omega_{k} i+\sum_{k=S+F+1}^{N} \omega_{k} j
$$

where $\omega_{k}\left(k=1,2, \cdots, N, \sum_{k=1}^{N} \omega_{k}=1\right)$ is the weight of the characteristic.

\section{Simulation example}

Having established the assessment index system and assessment process of equipment development risk, the comprehensive assessment of equipment development can be carried out in combination with the actual situation of equipment development. The original data used in assessment is shown in Table 1.

Table 1 Original data of equipment development risk assessment

\begin{tabular}{|c|c|c|c|c|c|c|c|c|c|c|c|c|}
\hline $\begin{array}{c}\text { Origina } \\
\text { Indices data }\end{array}$ & 1 & 2 & 3 & 4 & 5 & 6 & 7 & 8 & 9 & 10 & 11 & 12 \\
\hline Military attitude & 84 & 64 & 92 & 83 & 97 & 67 & 75 & 98 & 88 & 77 & 80 & 92 \\
\hline Market demand & 79 & 96 & 87 & 89 & 84 & 93 & 92 & 85 & 88 & 88 & 86 & 84 \\
\hline $\begin{array}{c}\text { Technical } \\
\text { storage }\end{array}$ & 78 & 94 & 87 & 85 & 78 & 91 & 18 & 93 & 74 & 83 & 80 & 76 \\
\hline $\begin{array}{c}\text { Talent } \\
\text { Introduction }\end{array}$ & 94 & 87 & 96 & 90 & 98 & 82 & 92 & 97 & 92 & 85 & 91 & 89 \\
\hline $\begin{array}{c}\text { Technological } \\
\text { level }\end{array}$ & 84 & 75 & 87 & 79 & 95 & 81 & 79 & 92 & 76 & 81 & 74 & 95 \\
\hline \begin{tabular}{c} 
Material supplies \\
\hline $\begin{array}{c}\text { Technology } \\
\text { innovation }\end{array}$
\end{tabular} & 86 & 89 & 77 & 83 & 75 & 91 & 88 & 79 & 80 & 86 & 82 & 79 \\
\hline $\begin{array}{c}\text { Test } \\
\text { identification }\end{array}$ & 92 & 87 & 95 & 91 & 97 & 89 & 97 & 96 & 95 & 91 & 90 & 98 \\
\hline $\begin{array}{c}\text { Budget } \\
\text { expenditure }\end{array}$ & 95 & 97 & 92 & 94 & 90 & 96 & 95 & 91 & 92 & 95 & 93 & 92 \\
\hline \begin{tabular}{c} 
Cost control \\
\hline $\begin{array}{c}\text { Project } \\
\text { management }\end{array}$
\end{tabular} & 90 & 85 & 94 & 92 & 98 & 80 & 89 & 97 & 94 & 90 & 87 & 93 \\
\hline $\begin{array}{c}\text { Evaluation } \\
\text { supervision }\end{array}$ & 92 & 97 & 85 & 84 & 95 & 83 & 94 & 91 & 90 & 97 & 94 & 92 \\
\hline
\end{tabular}

The assessment criteria of partial indices in equipment development risk assessment index system are shown in Table 2.

Table 2 Assessment criteria for equipment development risk

\begin{tabular}{|l|c|c|c|c|c|}
\hline Indices & Risk level & II & III & IV & V \\
\hline Military attitude & $<60$ & 70 & 80 & 90 & 90 \\
\hline Market demand & $<80$ & 85 & 90 & 95 & 95 \\
\hline
\end{tabular}

The weight vector corresponding to each index can be calculated by analytic hierarchy process according to the expert's experience:

$$
\begin{array}{r}
{\left[\omega_{1}, \omega_{2}, \omega_{3}, \omega_{4}, \omega_{5}, \omega_{6}, \omega_{7}, \omega_{8}, \omega_{9}, \omega_{10}, \omega_{11}, \omega_{12}\right]=[0.044,0.067,0.086,} \\
0.086,0.170,0.060,0.090,0.032,0.087,0.087,0.142,0.050]
\end{array}
$$


In Table 2, I, II, III, IV, V denote Very high risk level, High risk level, Medium risk level, Low risk level, Best risk level respectively. For military attitude, 60,70,80,90,90 denote I [0,60], II $(60,70]$, III $(70,80$ ], IV $(80,90], \mathrm{V}(90,100)$ respectively. The rest of the other indices are the same.

According to SPA, the data in Table 1 is substituted into the connection degree formula, and the total connection degree of each data sample can be calculated. The results are shown in Table 3.

Table 3 Total connection degree and its assessment criteria of each level

\begin{tabular}{|c|c|c|c|c|c|c|}
\hline Level & V & IV & III & II & I & $\begin{array}{c}\text { Assessment } \\
\text { level }\end{array}$ \\
\hline 1 & 0.1745 & 0.2012 & 0.3614 & 0.1184 & 0.2715 & III \\
\hline 2 & 0.1524 & 0.2063 & 0.1850 & 0.0651 & 0.3552 & I \\
\hline 3 & 0.1245 & 0.2953 & 0.2234 & 0.0822 & 0.1530 & IV \\
\hline 4 & 0.0510 & 0.0794 & 0.3225 & 0.1021 & 0.0640 & III \\
\hline 5 & 0.3712 & 0.1503 & 0.1221 & 0.1615 & 0.0503 & V \\
\hline 6 & 0.1209 & 0.1327 & 0.2042 & 0.2121 & 0.3520 & I \\
\hline 7 & 0.1059 & 0.2005 & 0.1132 & 0.4243 & 0.1128 & II \\
\hline 8 & 0.3120 & 0.2685 & 0.2121 & 0.0155 & 0.0562 & V \\
\hline 9 & 0.1762 & 0.3208 & 0.1435 & 0.1206 & 0.0824 & IV \\
\hline 10 & 0.1254 & 0.2121 & 0.1245 & 0.3035 & 0.1247 & II \\
\hline 11 & 0.1258 & 0.0475 & 0.4242 & 0.2120 & 0.0422 & III \\
\hline 12 & 0.2162 & 0.3416 & 0.1315 & 0.1132 & 0.1044 & IV \\
\hline
\end{tabular}

\section{Conclusions}

An assessment method based on SPA analysis is proposed for equipment development risk. In the method, firstly, the index system of equipment development risk assessment is established, and then on the basis of this system SPA is introduced to carry out the equipment development risk assessment. The case analysis result shows that, the proposed method can obtain a good result, improving the assessment effect of for equipment development risk, which provides a new approach for risk assessment of equipment development.

\section{References}

[1] Z. Xu, Y. C. Feng, D. W. Lu. Appraisement model of technical risk for weapon system development. System Engineering and Electronics, 27(6), (2005), 1123-1127.

[2] C. L. Song, L. Yan, J. L. Li. The application of the method of entropy-weighted double base point in risk assessment of weapon system development. Journal of Beijing Institute of Technology, 5(5), (2003), 77-79, 88.

[3] S. C. Zhang, Y. WanG. The risk evaluation of armament research based on FAHP method. Journal of Ordnance Engineering College, 27(2), (2012), 19-24.

[4] S. C. Tian, L. Wang, H. X. Li. Application of risk evaluation in coalmine gas hazard based on model of SPA. Journal of Safety and Environment, 6(6), (2006), 103-106.

[5] H. J. Xu, B. Gong, D. S. Li. Risk assessment of coal mine based on set pair analysis. Journal of Safety Science and Technology, 8(6), (2012), 86-90. 